\title{
The Attractive Territory: Contribution of the Territorial Positioning and the Innovative Theoretical and Historical Models
}

\author{
Baha Eddine Harroussi (PhD Student) \\ Abdellatif Chakor (Professor of Higher Education) \\ Mohammed V University, Faculty of Juridical, \\ Economic and Social Sciences - Souissi, Rabat, Morocco
}

Doi:10.19044/esj.2019.v15n10p43～㞷L:http://dx.doi.org/10.19044/esj.2019.v15n10p43

\begin{abstract}
This paper focuses on all the classic strategies of positioning throughout history that certainly generates the concept of innovation to positioning policies. To this end, innovation takes its organizational concept to be adapted to the marketing issue especially to the territorial thing. This is for the purpose of constituting an attraction for the targets including economic activities. This attraction is not a permanent situation; on the other hand, the territory must consolidate its competitive state to build an attraction in its permanent notion. The mobile state of the economy, which encourages territories to be attractive and competitive, is explained by several concepts, including economic globalization and the fluctuation of capitals. In this paper, we will explain several notions of attractiveness with a broad presentation of both economic and territorial attractiveness concerning investments. For this purpose, positioning refers to an antecedent notion of attractiveness which is seen as a marketing process. It is aimed at adapting the territorial offer to the aspirations and motivations of investors and the impact and contribution of the innovative idea in the process.
\end{abstract}

Keywords: Territorial positioning, territorial attractiveness of investments, innovative positioning, classico-historical models, territorial innovation

\section{Introduction}

In the course of history and in a context of rehabilitation, researchers and leaders strive to boost the economic attractiveness of their regions to investors. This strategic vision is guaranteed by shaking up the directives and practices in order to grasp a striking position of opportunity and to revolutionize the reasoning towards territories. 
A position is never permanent, and investments are not tied to a territory although they are linked to economically territorial conditions. This explains why capital is defined by fluctuation and immediacy, and that the attraction of investment implies rethinking organizational innovation.

History takes a wide place in the concept of innovation in favor of the territory via the Fordist model, the Marshall Industrial District, local productive systems, and the innovative environment.

\section{- The Territory between Competitiveness and Sustainable Attractiveness}

\section{a. The explanatory concepts of the transfer of capital}

The globalization of the economy has introduced a giant transformation in the fluctuation of capital and skills. However, multinationals are still rethinking to locate themselves in emerging territories. This transformation is explained by five major concepts.

\section{i. Internationalization and multinationalization of firms}

Companies are becoming more internationalized in finality to conquer other markets in order to increase their market share and to seek competitive advantages or even to have resources at lower costs. The choice of localization is the result of an exhaustive decision-making process that involves competing territories.

ii. Increased competition between the territories

The territory has become a product that needs to be valued and appreciated, and the innovative incubators have stimulated a feeling of rivalry in other territories. These incubators have exploited the competitive advantages of their territories in terms of resources to build attractions for investors.

\section{iii. Mobility}

Inertia is an aspect that no longer exists. An actor who is a person, an investor, and/or a multinational can change location according to the attractiveness of a territory. Innovative ideas are not permanently acquired. Innovation is also a mutable concept according to socio-economic circumstances and evolutionary ambitions. In addition, the world has seen giant changes in the motility of skills, households, businesses, factors of production, trends ... etc.

\section{iv. The fugacity}

The data became an imperative component in the decision-making of the various partners and actors of the territory. The updated information has 
exceeded the limit of utility towards the bound of the imperative. It has become computerized and available on a simple click; yet, the emerging territories are referring to the scientific and technological research. The example of "Yaoundé: project leaders of students" (Francis \& Régis, 2009) explains in strong terms the importance of exploiting science and technology especially for developing countries.

\section{v. Transformation of actors' behavior}

A territory must surely respond to the devices of mobile partners and continually attract potential partners. This puts local decision makers in the demand to create competitiveness and innovation clusters under the term of new industrial policies (NIP) with the exploitation of scientific and technological research.

\section{b. Territorial attractiveness: A look at several visions}

The territories are putting themselves in the imperative of being aware of the upheaval of the economy and world politics. However, an attractive territory will not always be attractive if it remains inert. On the other hand, a competitive territory is defined by its quality and its sustainable attractiveness. For this purpose, attractiveness can be defined as the ability of a geographical area to attract people and skills and to have firms set up while offering these actors the optimal conditions for locating themselves in this geographical space. According to the Organization for Economic Co-operation and Development (OECD, 2005), attractiveness is defined as "the ability to attract skilled labor and skills as means to foster economic development and urban regeneration". In addition, "attractiveness is the ability of a territory to offer actors the conditions that convince them to locate their projects on their territory rather than on another" (Hatem, 2004b). The attractiveness of the territory includes seven elements.

Furthermore, the attractiveness of the territory is measured according to its nature and the number of both hotel occupations and passengers entering the train stations and airports. A tourist territory is seen as a case in point. The brilliance and the number of cultural and festive events evaluate a cultural territory.

\section{vi. Economic attractiveness}

It is the ability for a territorial offer to provide investors with the favorable conditions which persuade them to be located in any territory. The economic attractiveness of firms may initially concern economic, financial, and monetary benefits as well as the business and investment environment. 
vii. $\quad$ Tourism and ecological attractiveness

The tourist territory is now attractive by its natural and cultural characteristics. Nevertheless, the making of the offer is a necessity to build a territorial quality in order to attract the users and the investors forming part of the tourist mission. Our Kingdom is a touristically attractive destination, but it was necessary to review the image of some perimeters and the positioning of the isolated regions that constitute a complementary product in favor of the notorious cities. On the other hand, ecology is a sector of tourism. Its attractiveness is considered as a pillar for the benefit of the tourist territory and it concerns, for the first time, the natural ecosystems (even the natural parks and the biological reserves) and the urban ecology (even ecological gardens and green spaces).

\section{viii. Cultural attractiveness}

It resides in the upkeep and revalorization of festive activities and events, as well as in the cultural appearance and historical monuments that make up the identity and image of the territory. According to UNESCO, culture "is an engine of growth through the creation of employment, production and investment". The creative and artistic class is then an asset in favor of the incubator for building a creative territory. In addition, the cultural brilliance constitutes an endogenous force for the benefit of the territory and the clarification of its positioning. It also allows stimulating the motivation of the creative and artistic class.

\section{ix. Residential attractiveness}

Families are looking for a city that is beneficial to households, a city that has jobs, telecommunications, and transportation infrastructure. They are attracted to a favorable geographical area in terms of climate, ecology, and well-being. Territorial marketing is a tool for analyzing the behavior of the inhabitants. Thus, the future of their children and their welfare (well-being) are priorities for the attractiveness of households. Residential attractiveness is linked to social participation, social support, social influence, social inclusion and access to resources, and benefits of the territory.

\section{x. Technological attractiveness}

The technological concept consists of the attraction of technological activities and Research and Development ( $R \& D$ ) hubs, as well as the new information and communication technologies (NICT) which constitute an important part. Emerging territories rely primarily on technological innovation, but territorial management based on new technologies seems necessary for territorial development. Technologies have disrupted territories and modulated the stakes of local power; they have certainly facilitated access 
to new knowledge and access of local actors to the public service. In fact, the attractiveness of technology providers creates what is called the combination of technological data and a synergy of technologists in order to increase the process of technological innovation of the territorial offer. It also makes it possible to reinforce the co-operation between the actors (collective intelligence) so as to provide the territory with a development in favor of future generations under the notion of sustainable development.

\section{xi. $\quad$ Scientific attractiveness}

It refers to the attractiveness of scientific careers, researchers, and students through the constitution of research teams and the involvement of science. The relationship between humans always has a significant impact on the social atmosphere. "The Silicon Valley Model" (Francis \& Régis, 2009) has become a benchmark for innovative incubators at universities and training schools. "Silicon Valley has achieved a unified and coordinated device and a focused Strategy via network activation of experts and decision makers" (Francis \& Régis, 2009). The scientific attractiveness optimizes the meeting of ideas and competent faculties. It also promotes organizational innovation that represents an opportunity for users and stakeholders in the field of scientific input and organizational creativity. However, the question is, "Does a territory undoubtedly offer a captivating living environment for researchers, engineers and senior executives, while having the best conditions, transportation and telecommunication conditions?"

\section{c. The attractiveness of economic activities in the broader sense}

For an economic territory, indicators represent the measure of its attractiveness or even corporation tax (IS) of foreign multinationals setting up their headquarters in a geographical area and the number of companies installed in the agglomerations and investment projects from abroad. Foreign direct investment is a basic and decisive indicator for assessing the accessibility of investors outside a territory. Being attractive is not eternal, but it is not ephemeral. Sustainable attractiveness needs to be adaptable to the upheavals of the world economy, especially since the territory is an essential element of change and a major representation of the upheavals defined by globalization and the desire to evolve.

Consequently, developed countries are expanding through symbolic production, agglomeration dynamics, and industrial innovation. Agglomeration dynamics encourages the attraction of projects and investments through partnership dynamics, innovation, involvement of partners, and endogenous development. Moreover, among these phenomena of agglomerations are "clusters, local productive systems (LPS), industrial districts, technoparks, competitiveness clusters, multi-purpose agglomerations 
(or metropolises), and the specialized agglomeration (or metropolitan areas)" (Hatem, 2007). We have just mentioned the phenomena of agglomerations in order to cite their attributions and their roles in territorial attractiveness.

The phenomenon of agglomerations creates a favorable investment environment through an exhaustive territorial offer (infrastructures, research and training centers, financial resources, upstream and downstream partners, scientific skills, etc.). Moreover, the territory is largely attached to its partners as was stated: "Here, the capacities of enterprises, territories, and societies are associated with the activities of entities" (Sherzod, 2017). This encourages external actors to create commercial relations with partners of the so-called territorial, and it irrigates the concept of territorial innovation via the naming and the implication of the competences. This also irrigates the function of the territorial positioning and influences their decision of localization.

On the other hand, there are several policies of valorization of the territorial offer such as:

- Road and telecommunication infrastructures

- Training, scientific research, and access to technology

- High financial resources and low-cost human resources

- $\quad$ Price competitiveness and tax exemption

- The territorial mark and symbolic production

In addition, these concepts can be included in the concentric approach of attractiveness, which is illustrated in Figure 2 as follows:

Figure 1. The concentric approach of attractiveness (Hatem, 2008)

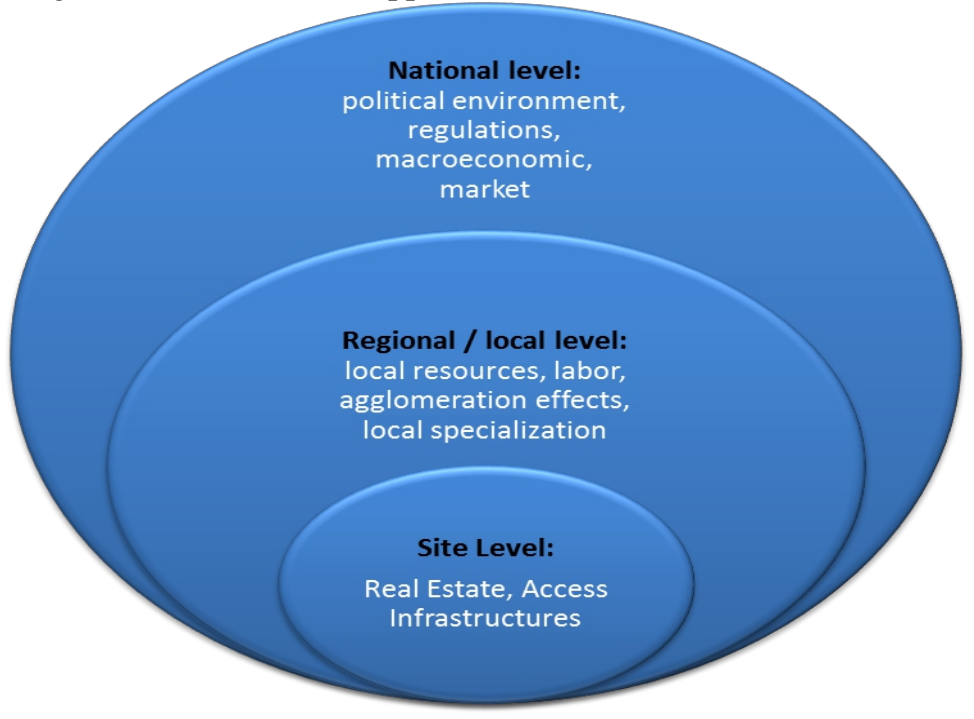

These policies are designated as tools in favor of the public structure to rethink the territory as a resource for large multinationals and a producer of wealth. In fact, these public actors take charge of the endogenous development 
of the territory. Endogenous development consists of establishing a regional platform of activity, creating "forms of competition-cooperation, relationships based on trust, affinity links with the local... These are supported at a level of power that allows actors to consult and to know each other" (Lamarche, 2003). The localization of the firms focuses the second time on the image-price approach, which otherwise clarified the competitiveness-attractiveness link. Admittedly, cost becomes a central issue as it differentiates one territory from the other.

Public intervention via symbolic production allows major city projects (MCP) and major urban projects (MUP) to be a territorial emergence. Concertation and contractualization are two central strategic models to enhance the sense of belonging to the territory, to rebuild a permanent quality, to stimulate the implementation of the promoters, and the reintegration of the actors of the territory.

\section{d. Sustainable attractiveness explained by competitiveness}

Competitiveness refers to the second notion that is debated in government and public meetings. In recent years, territorial competitiveness has become the concept that has aroused the interest of local governors, bearing in mind that a territory must be competitive to be attractive and viceversa.

The territorial competitiveness can also be measured according to the European Association of Development Agencies (EURADA) by the characteristics and the material and immaterial indicators such as:

- Workforce

- Transport and telecommunication infrastructures

- Innovation and research and development

- The economy of knowledge and the know-how

The juxtaposition between the notion of competitiveness, attractiveness, and territorial marketing is an axiom. States are open to the international world for implementing investments which has given rise to territorial competition. These territories are competing to establish driving attractions that optimize the competitiveness of the territory. The desire to attract investments and projects has obviously involved marketing strategies or even "the segmentation of supply, demand segmentation, positioning study, Benchmarking..." (Benabdelhadi \& Moussalim, 2012). Competitiveness strongly concerns several sectors (residential, commercial, tourist, economic, political, etc.) as well as attractiveness, which is why we are talking about sectoral territorial marketing and territorial project marketing.

Attractiveness or relocation (retention) of projects and investments is therefore linked to the competitiveness of the territory and its ability to 
persuade economic agents to set up their economic activities in a desired area, to mobilize skills, and to involve science, knowledge, and technology.

\section{e. The attractiveness of investments: Incorporation of three complementary dimensions}

The attractiveness of investments lies in the capacity of a territory to captivate and safeguard investors through the operation of a skillful mechanism. Indeed, the territories must take care of preserving the investments and revitalizing themselves of the best characteristics of attraction. In the figure below, we will identify the three dimensions that interact to define the territorial attractiveness of investments.

Figure 2. Incorporation of the three dimensions of territorial attractiveness

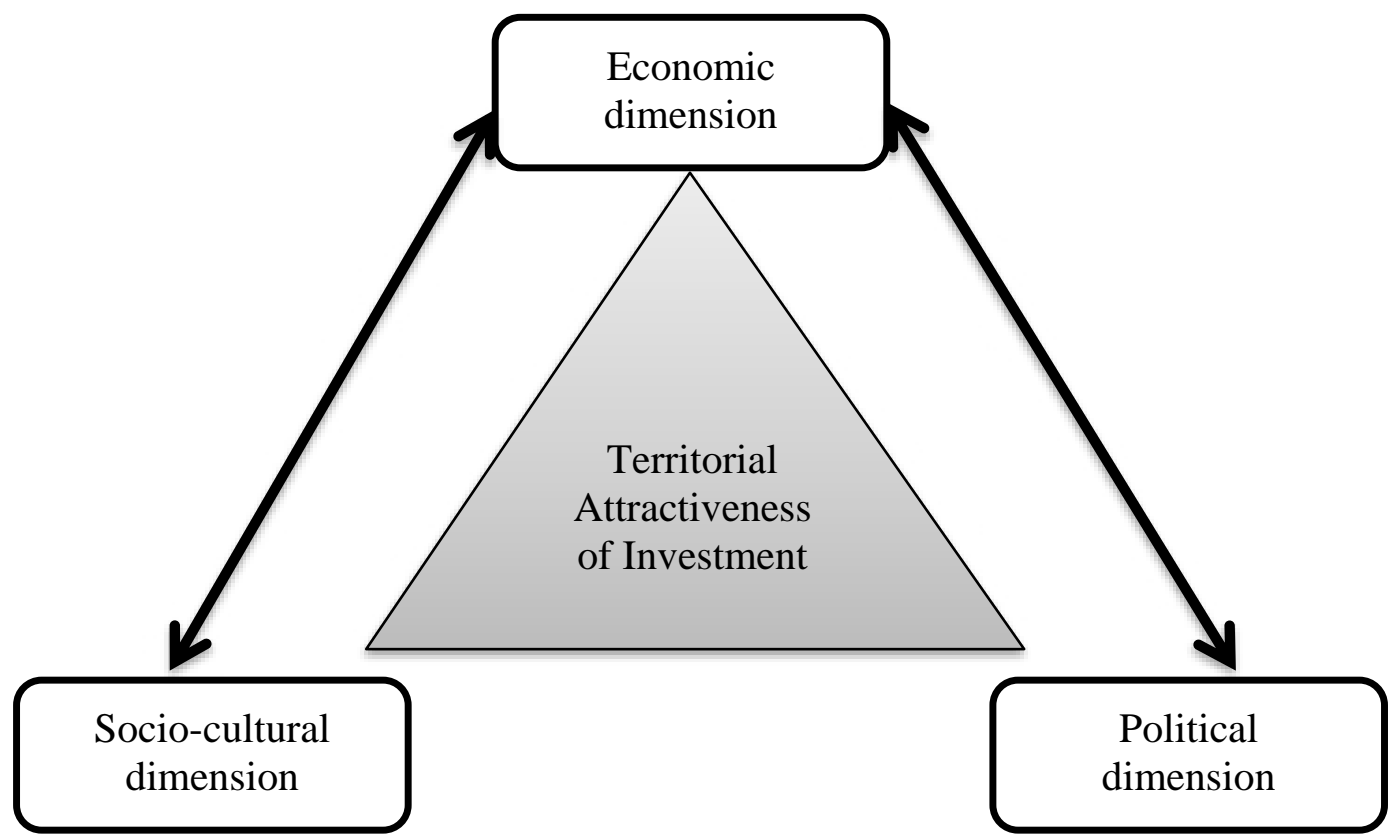

xii. The economic dimension

The economic dimension refers to the physical and financial strength for the purpose of protecting investors and developing a favorable environment for each category of investment or investor. This is a fundamental component in the location decision. 
Table 1. Parameter of economic dimension

\begin{tabular}{|c|c|}
\hline Parameter & Meaning \\
\hline Stock of investments & The effects of agglomerations \\
\hline GDP growth rate & Economic growth of domestic investments \\
\hline Gross domestic product per capital & $\begin{array}{c}\text { Economic development (the wealth of a } \\
\text { territory) }\end{array}$ \\
\hline Gross national savings & Dependence on foreign capital \\
\hline Real exchange rate & Economic volatility \\
\hline Internal investment rate & Internal investment level \\
\hline Inflation rate & Living standards of inhabitants and citizens \\
\hline
\end{tabular}

xiii. Socio-cultural dimension

The socio-cultural dimension is particularly complex and its control is so rigid because it encompasses the meanings related to the society of the territory namely:

- The standard of living of society

- Educational level and educational system

- Feedback to a new market and a new way of life

- The quality of skills and talents

Table 2. Parameters of socio-cultural dimension

\begin{tabular}{|c|c|}
\hline Parameter & Meaning \\
\hline Index of human development & The level of human development \\
\hline Urbanization rate & The development of urban institutions \\
\hline Number of telephone lines & Level of infrastructure development: \\
& Telecommunication \\
\hline
\end{tabular}

xiv. $\quad$ Political dimension

The political dimension is a dimension relative to investments towards countries, especially foreign territories, such as FDI (Foreign Direct Investment). For this reason, this dimension is crucial as a result of the parameters to be analyzed in order to analyze the possibility of installing investment projects in the targeted territory.

Table 3. Parameters of political dimension

\begin{tabular}{|c|c|}
\hline Parameter & Meaning \\
\hline Global index of economic freedoms & Levels of Government Constraints on the \\
& Economy \\
\hline Global Index of Political Rights & Level of democracy \\
\hline Global Index of Civil Liberties & Freedom of expression, law \\
\hline
\end{tabular}

xv. General model of the territorial attractiveness of investments

These dimensions are so complementary and interacting that each dimension acts on the others and vice-versa. More so, each situation can be changed in one go. 
Of which:

- DIMPOL: The political dimension

- DIMECO: The economic dimension

- DIMSOC: The socio-cultural dimension

- $\mu=\mathrm{c}+\mathrm{e}, \mathrm{c}=$ constant, $\varepsilon$ is the error term

- $\alpha, \beta$ and $\delta$ : the parameters

(b) Positioning: An Antecedent Notion of the Territory

"Win the battle of the spirits to win the battle of the market" (Lewi, 2010). The positioning is certainly designed for strengthening the attractiveness of the territory. Positioning is an initially public affair and a strategic reflection of the efforts of an arsenal of public stakeholders.

Positioning is also a voluntarist approach of the territory that consists of choosing where we are located in a market in front of competitors and with clear value proposition for the customers. Positioning is what we want in the minds of investors; it is the facet chosen and wanted which must be continuously optimized to commercialize a favorable image of the territory. This is with the aim of maximizing their attractiveness, cities segment and select areas where they have advantages and where opportunities are most favorable (Proulx \& Tremblay, 2006). In fact, the territorials seek to rely on the forces of the territory with the imperative to modify and shape the offer.

Positioning a territory means "optimally highlighting its advantages (real or perceived), which are the most differentiating, compared to the communities defined as competitors and to the public for whom this difference is motivating" (Sperling, 1991). Positioning is considered a capital of the territory's strategy. In addition to the fact that firms are seeking to conquer emerging markets, local actors need to be aware of how their territory is perceived.

The territory itself has objective traits that characterize them (climate, history and its value, identity and image, territorial branding, partners and actors, infrastructure, geographical location... etc.), but it can acquire a positioning under the conception of the public effort. Hence, the positioning consists of "conferring to a territorial offer salient features likely to make it attractive" (Meyronin, 2009) in the eyes of the targets, differentiating as much as can be made offers of competing territories. The territory can be favorably positioned by the indicator of the high quality of life. Thus, this is despite the fact that the positioning is based on the two major meanings of identification and differentiation. The relationship between the actors of the territory is a necessity to build a readable positioning. In addition, the image of the territory is the consequent notion of positioning. 
Consequently, the identity positioning of the territorial space "consists of privileging certain factors and certain dimensions" (Bourkache \& Tessa 2015). The illustration (Figure 3) below states that the positioning is an antecedent to the territorial mix, and that it brings together the strategy of the territory and the territorial mix.

Figure 3. The six (6) policies of the territorial mix and their relationship with the territorial positioning (Benabdelhadi \& Moussalim, 2012)

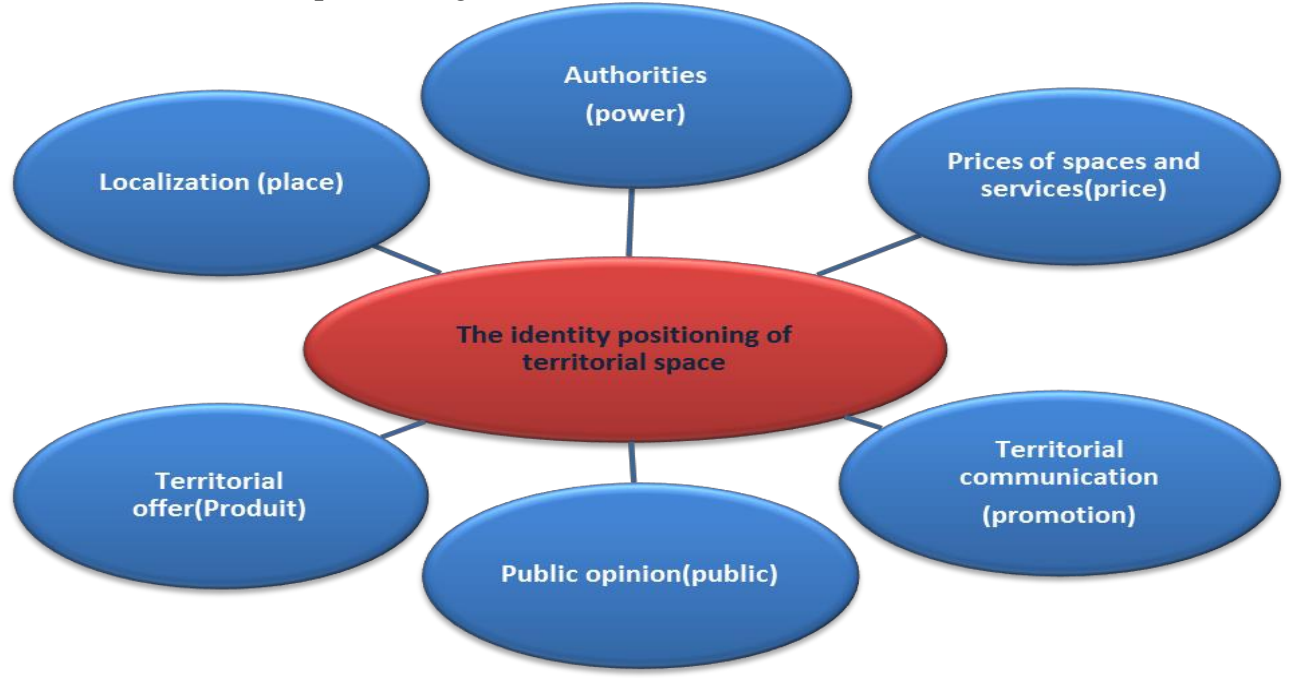

In fact, the competitive positioning of a territory must be credible and distinctive in order to attract, welcome, locate, and retain users who will produce benefit and who will fuel innovation. This can be achieved through the concept of research and development (R \& D) and the participation in economic activities.

The shaping of the faculty of positioning requires an arsenal of devices to take into account:

1. Landmarks (the antecedent characteristics of the territory)

2. The wealth, size, and resources of the territory

3. The state of the place

4. The quality of life of households

5. Targeted endogenous clientele

6. The requirements of the customers established in the perimeter of the territory

Rethinking the shift in positioning fuels the drive for transformation and, subsequently, this change must be aware of the turmoil around the world. The research and the accumulation of knowledge are the central resources for the elasticity and the durability of this change.

Also, territory and economic agents fulfill the reciprocal function of positioning. While the territory has an impact on the actors, these partners 
themselves influence the image and identity of their territory. Therefore, companies feed the territory through the creation of networks and participation in various economic activities. The choice of the endogenous clientele is an antecedent notion of positioning. Nevertheless, we must think of the "law of innovation" (Francis \& Régis, 2009) of new industrial policies (NIP) which impose on symbolic incubators the creation of companies by researchers and startups. On the other hand, the positioning must target the actors along with the inhabitants and the tourist passengers. That is to say, the local decision maker must apply a differentiated marketing adapted to each target.

\section{f. Categorization of positioning}

xvi. $\quad$ Positioning policies

\section{Overall positioning}

This positioning category acts on the reputation and the image of the territorial offer. It entails the project of targeting all the established partners and the potential economic agents by valorizing the resources and the assets of the territory in the eyes of the targets. Rabat and Tangier are concrete examples of this type of positioning since they are cities aiming to position themselves to the minds of tourists, firms, multinationals, SMEs, hotels and tourist establishments... etc.

\section{2. $\quad$ Adapted positioning}

It is about building its promise for each targeted segment or for a few well-defined segments whose objective is to adapt the offer to endogenous customers and to optimize their favorable conditions. For example, Marrakech is a city which targets tourists, tourist institutions, and confers. On the other hand, Casablanca attracts multinational companies and major carriers of projects and investments.

\section{Positioning of the local actor}

The purpose of this positioning is to improve the position of the local authority with regards to targeted investors. Generally, this category of positioning has been exceeded as it is neglecting the attractiveness and the competitiveness of the territory. It is also articulated on the purpose of the local actor to understand how it is perceived.

\section{xvii. Positioning strategies}

\section{Positioning by geographic location}

The location of the territory is a defining characteristic in the design of the positioning. Indeed, local decision makers exploit specialization to demonstrate geographic advantages. The city that constitutes the center or the capital relies, among other things, on the quality of infrastructures and state 
institutions (training establishments, hospital centers, prefectures, etc.). This makes it possible to represent a pole image of commercial transactions. Rural destinations can be characterized by their natural and ecological attractiveness through their ecosystem environment.

\section{Positioning by economic benefits}

The territories that offer this type of positioning are certainly located at the center of a region. Moreover, these territories provide financial and monetary benefits in terms of subsidies, tax, credits, etc... Spatial proximity is one of them. The territory that has an investment environment attracts endogenous actors and is a driving force for business.

\section{Positioning by human resources}

Human resources are proving to be a device statement par excellence. This explains the importance of man in the territorial mission. However, training and transfer of knowledge are two crucial components of creating the desired man. The reputation of training, education, and scientific research irrigates this kind of positioning, although the educational and informative system is an antecedent of human skills and aptitudes. In addition, to rethink the fabric of the creative city, it is imperative to adopt the creative class and young artists.

\section{Positioning by infrastructure benefits}

Large urban projects and large city projects rely on large government institutions. Indeed, the existence of these infrastructures constitutes a strategic resource and traction of investments. Today's innovative incubators have set up an economic platform to serve the territory's stakeholders. The Italian school has defined the industrial district as being the concentration of small and medium-sized enterprises around a dominant industry. Nevertheless, it can be said that the concentration of firms or even multinationals is related to a strong logic to the infrastructural devices of the territory.

\section{Positioning by technology}

Shaijumon has approached in his paper that "technology may be partially a public good, but that it is largely a specific good" (Shaijumon, 2014) and through theory, economic development needs to adopt new technology of information and communication. Otherwise, economic development would implicate adopting technologies and co-evolution of knowledge. 


\section{(c) Innovation at the Core of New Positioning Strategies}

\section{g. The innovative conception}

At first glance, organizational innovation design draws its direction and instruction from marketing. This means that the link between marketing and innovative design brings out new insights and information about the operated market including the users. As an experiment by researchers, today we are living in a third age of the economy where knowledge is the main factor of production (Otando \& Echkoundi, 2008).

As Cohen (2004) points out, "it is the upstream and downstream activities that are the design and prescription that now occupy the essential place. At the first end of the value chain, there is the production of intangible goods". At the other end of the value chain are face-to-face activities (Cohen, 2004). Intangible goods which involve knowledge and know-how constitute an asset in favor of territorial innovation. In essence, "research becomes a necessity in the way of mobilizing the territories".

Joseph Aloes Schumpeter was the first economist that approached the theory of innovation in the economic field. For this reason, his forerunner contribution constitutes an inspiration for the ulterior theories of innovation. Moreover, innovation is considered as a different strategic solution for all the economic issues, although it varies according to the reaction of competing offers.

"According to Schumpeter, the entrepreneur is the innovator par excellence who combines in a different way the production means" (Passaro, 2017). This citation is made explicit that the investor, the startup or the entrepreneur is a scientific career that can contribute to the innovative ideas and bring some new offers. The majority of scientific careers pay a lot of attention to technological and scientific innovation. Nonetheless, innovation can strongly concern the organizational and commercial aspects via the contribution of new concepts and techniques. This is in accordance with Passaro's paper. The inventor's attention is, therefore, in science and technology as knowledge's assets. Besides, innovation is not necessarily derived from an invention and, differently from the latest one, it allows taking a commercial advantage defined as monopolistic asset from innovation (Passaro, 2017).

\section{h. The Fordist Model}

The innovative design of marketing provides the positioning function with the motor guidelines to rethink and set up symbolic incubators and innovative and intelligent platforms. In addition, the emerging territories were inspired by the Fordist model which "remains centered on large projects, large innovation, and growth-generating complexes which are expected to have diffusion effects on subcontractors and SMEs in the neighborhood" (Guesnier, 
2016). The territory itself is largely a propitious and is timely spaced to excel innovation. "Thus, in the face of the inability of the standard theory to account for this spatial shift, new approaches are focusing on the territory as a place for ultimate innovation" (Otando \& Echkoundi, 2008).

\section{i. The Marshallian District}

The industrial district which first appeared in 1898 in A. Marshall's Principles of Political Economy was the sense of industrial and territorial ultimate reform to approach new industrial policies (NIP). On the other hand, intelligent incubators always seek to establish firms and industries. Thus, they aim to create supportive platforms inspiring these industries. By way of logic, the economic literature provides that the territory is ultimately a suitable place to bring innovation practices, and it also plays a central role in the profile of decentralization and innovation. On the other end, the territory seeks to recruit the creators of the innovation. Accordingly, the territorial space and the firms fill reciprocally the function of the innovation whose co-contribution is a necessity.

The Marshall Industrial District introduced the concept of agglomeration economies, which is defined as "the concentration of many SMEs focused on specializations around a dominant industry" (Otando \& Echkoundi, 2008). The notion of the industrial district or the Marshallian district is a geographical and economic concept that relates to a place, which is used to facilitate the complementarity of skills. From this effect, the industrial district constitutes an innovative antecedent and a historical reference based on the benefit of the function of the positioning of the territories. Thus, it allowed the density of the companies around a territory. The notion by which this is explained shows that it feeds the scientific research for the resumption of the current economies of agglomerations, the industrial district which affects the economic literature, and the territorial thing which determines the new forms of the positioning.

\section{j. The local productive systems: combination of Fordist and Marshallian model}

By way of a combination, the Fordist model and the Marshallian district inspired the new industrial policies. Both of these models have grounded innovative ideas for marketing positioning and have introduced the idea of agglomeration economies and stakeholder networks or even local productive systems (LPS). These are defined as "a configuration of companies grouped in a local area around a trade, or even several industrial trades. Companies maintain relations with each other and with the socio-cultural environment of innovation. These relationships are not only commercial; they are also informal and they produce positive externalities for all businesses" 
(Courlet \& Pecqueur, 1992). The concept by which we want to explain the model of LPS is the creative economy, which relies on cultural projects to establish creative industries bringing new offers.

\section{k. The innovative space}

The territory constitutes a place of exploit for the local productive systems. It also makes it possible to establish economies of agglomeration due to the concentration of the firms and to the production of the innovation. In addition, festive and cultural events allow the density of creative actors around a territory and play the role of symbolic incubators for the contributors of innovation. Therefore, we can see that the firm is not an isolated innovative player, yet it is a component of an "innovative environment" (Otando \& Echkoundi, 2008). In other words, the endogenous development of an incubator requires the federative institution of an innovative platform that optimizes the transformation of innovative data and new knowledge.

\section{The contribution of innovation to territorial positioning}

Innovation has become a leitmotif of all those who are concerned by the territory. In addition, it is an endogenous factor for the benefit of territories, cities, and countries to initiate new policies of territorial reconversion. Consequently, the emerging countries seek to import the contributors of innovation in the direction of technology. This is more explicated by Zaoual (2006, p.136), who stated that "the countries that sought to develop were encouraged, for economic reasons, not to develop their own capacity to innovate, but rather to import the most advanced technology as massively as possible" (Zaoual, 2006).

The global upheaval, the economic turbulence, and the persistence of the territories have involved, in this case, new ideas and new management systems in order to perceive differently the territorial reform. Additionally, "many researchers are unanimous on the fact that the contemporary economy is at the crossroads of several changes that transform it from top to bottom" (Otando \& Echkoundi, 2008).

The relocation of companies has become a fact that threatens the territories as economic and political rivalry. The territories are also at the crossroads of the economies of agglomerations and clusters that the persistence of central institutions has become weak. This is due to the fact that decentralization has never been adopted as innovation at the level of organizations.

Decentralization is a form of organizational innovation that gives local governors, in this case, the strategic and decisive position for refining territorial performance. This can be likened to a farmer who analyzes his clod of land and opts for ingredients performing. 
Innovation is a concept that reunites institutions with people. "Innovation is not just about institutions, it is also a concern for all men and women" (Sylvain, 2016). Furthermore, public intervention remains imperative to supervise inventive and innovative contributors to be incarnated like the incubator, and to set up motor projects through the construction of an economic and social platform. In the same way, the creator of the small firm is another essential and indispensable substance in the measures taken for the practices of the innovation. The theory of the notion "The law of innovation" (Francis \& Régis, 2009) implies the creation of companies by researchers. This idea is capital. The territory largely draws profits and profiles of the dynamics and technological advancements of firms and actors reproducing wealth and innovation. The big firms have also focused on the innovative contributions of startups.

In the past, innovation in the classical sense can be seen in terms of technology, industry, and scientific research. However, the effect of the economic and territorial slump has forced governments to cultivate innovation policies. This is in addition to the fact that innovation concerns information and communication technologies as well as organizational creativity.

Moreover, this shows the impact of the territory on the behaviorist aspect of the actor according to the theories of the psychology of man. Aydallot (1985) also agrees that man is in the behavioral paradox. Human behavior also differs by the difference of environment. Moreover, an innovative environment optimizes the intervention of man. This explains the critical role of the state by its decision-makers and governors in the dynamics of innovation.

\section{Conclusion}

This paper reminds us of the notion of territorial positioning which is considered as the intermediary parameter between the invisible component (study, research and marketing analysis, segmentation, etc.) and the visible part (territorial mix policies, the operational phase) of the marketing process.

Additionally, positioning must be attractive to the extent that it is attractive to the targeted segments. For this purpose, the concept of attractiveness has been insinuated with different visions and meanings. In addition, the concept of positioning with its classifications and its stage in the marketing process has been stated in clear terms. Also, the historical models that feed the literature of economic, industrial, and territorial intelligence have been identified.

This paper made an attempt to mention that the territorial attractiveness of investments is a purely variable and unstable concept, whereas this variability is explained by several concepts that have been cited. As a result, the territory must always have an insight into continuous investigations and 
inspections of the economic turmoil. We also explored a set of historical models that tried to resist the upheaval and the scientific impact of territorial marketing positioning and its theoretical contribution to the shaping of the territorial offer.

\section{References:}

1. Benabdelhadi, A. \& Moussalim, S. (2012). Le marketing territorial Cas de la région de l'Oriental, Revue Marocaine d'Administration Locale et de développement.

2. Bourkache, F. \& Tessa, A. (2015). Le positionnement stratégique d'un territoire : quel apport du marketing territorial ?, Revue des Sciences économiques et de Gestion.

3. Braun, E. \& Van den Berg, L. (1999). Urban Competitiveness, Marketing and the Need for Organizing Capacity, Urban Studies.

4. Cohen, D. (2004). La mondialisation et ses ennemis, Pluriel, Paris.

5. Courlet, C. \& Pecqueur, B. (1992). Les Systèmes industriels localisés en France: un nouveau modèle de développement.

6. Daniel Sperling (1991). Le marketing territorial.

7. Francis, K. \& Régis, L. T. (2009). Clusters, pôles de compétitivité et pôles de développement: dimension territoriale et partenariale des processus d'innovation, attractivité gouvernance et développement.

8. Georges Lewi (2010). Construire une stratégie de marque pour un territoire.

9. Guesnier Bernard (2016). Décentralisation et innovation : le rôle central $d u$ «territoire ». Marché et organisations ( $\left.\mathrm{n}^{\circ} 25\right)$, p. 29-43.

10. Hatem, F. (2008). le marketing territorial: principes, méthodes, pratiques.

11. Hatem, F. (2007). Le rôle des clusters dans les politiques d'attractivité", l'attractivité des territoires : regard croisé, p. 19-22.

12. Hatem, F. (2004b). Investissement international et politiques d'attractivité.

13. Lucarelli, A. \& Berg, P.O. (2011). City branding: a state-of-the-art review of the research domain, Journal of Place Management and Development, Vol.4, p.9-27.

14. Maria, I. S. \& Buonincontri, P. (2011). Cultural Event as a Territorial Marketing Tool: The Case of the Ravello Festival on the Italian Amalfi Coast, Journal of Hospitality Marketing \& Management.

15. Meyronin, B. (2009). le marketing territorial: enjeux et pratique, 292 p.

16. Otando, G. \& Echkoundi, M. (2008). Innovation et dynamiques territoriales: une approche par le concept de l'innovation située. 
17. Passaro, P. (2017). Business Model in Air Transport: Evolution of Innovation Concept, European Scientific Journal, Italy Proulx M-U.

18. Tremblay, D. (2006). Marketing territoriale et positionnement mondial. Géographie, économie, société.

19. Shaijumon, C S. Institutions and technology diffusion in agriculture : role of Isro village resource centers, European Scientific Journal, India.

20. Sherzod, M. (2017). Investment Attractiveness of Regions: Methodic Aspects of the Definition and Classification of Impacting Factors, European Scientific Journal, Republic of Uzbekistan.

21. Sylvain, A. (2016). Innovation et territoire : l'exemple de ParisSaclay, Marché et organisations, $\left(\mathrm{n}^{\circ} 25\right)$.

22. Thomas, L. (2003). Le territoire entre politique de développement et attractivité, études de communication.

23. Zaoual, H. (2006). Management situé et développement local. Collection Horizon Pluriel, (213 pages), Rabat. 